Article

\title{
Evaluation of Recyclability of a WEEE Slag by Means of Integrative X-Ray Computer Tomography and SEM-Based Image Analysis
}

\author{
Markus Buchmann ${ }^{1,2, * \mathbb{D}}$, Nikolaus Borowski ${ }^{3,4}$, Thomas Leißner ${ }^{1}{ }^{(\mathbb{D}}$, Thomas Heinig ${ }^{2}$, \\ Markus A. Reuter ${ }^{2}\left(\mathbb{D}\right.$, Bernd Friedrich $^{3}(\mathbb{D})$ and Urs A. Peuker ${ }^{1}$ \\ 1 Institute of Mechanical Process Engineering and Mineral Processing, TU Bergakademie Freiberg, \\ Agricolastraße 1, 09599 Freiberg, Germany; thomas.leissner@mvtat.tu-freiberg.de (T.L.); \\ urs.peuker@mvtat.tu-freiberg.de (U.A.P.) \\ 2 Helmholtz-Zentrum Dresden-Rossendorf, Helmholtz Institute Freiberg for Resource Technology, \\ Chemnitzer Straße 40, 09599 Freiberg, Germany; t.heinig@hzdr.de (T.H.); m.reuter@hzdr.de (M.A.R.) \\ 3 Institute of Process Metallurgy and Metal Recycling, RWTH Aachen University, Intzestraße 3, 52056 Aachen, \\ Germany; nikolaus.borowski@sms-group.com (N.B.); bfriedrich@ime-aachen.de (B.F.) \\ 4 SMS group GmbH, Ivo-Beucker-Straße 43, 40237 Düsseldorf, Germany \\ * Correspondence: markus.buchmann@mvtat.tu-freiberg.de or m.buchmann@hzdr.de
}

Received: 10 February 2020; Accepted: 26 March 2020; Published: 30 March 2020

\begin{abstract}
Waste of electrical and electronic equipment (WEEE) is one of the fastest growing waste streams globally. Therefore, recycling of the valuable metals of this stream plays a vital role in establishing a circular economy. The smelting process of WEEE leads to significant amounts of valuable metals and rare earth elements (REEs) trapped in the slag phase. The effective manipulation of this phase transfer process necessitates detailed understanding and effective treatment to minimize these contents. Furthermore, an adequate process control to bring these metal contents into structures that make recycling economically applicable is required. Within the present study, a typical slag from a WEEE melting process is analyzed in detail. Therefore, the material is investigated with the help of X-ray computed tomography (XCT) and scanning electron microscopy (SEM)-based mineralogical analysis (MLA) to understand the typical structures and its implications for recycling. The influencing factors are discussed, and further processing opportunities are illustrated.
\end{abstract}

Keywords: waste of electrical and electronic equipment; X-ray computed tomography; mineral liberation analysis

\section{Introduction}

Over the course of the last few years, the pyro-metallurgical recycling process of electronic scraps, so-called WEEE (waste of electrical and electronic equipment), developed significantly not only because of governmental restrictions and statutory recycling rates, but also due to valuable and economically interesting amounts of metal contents (e.g., $\mathrm{Cu}, \mathrm{Au}, \mathrm{Ag}$ ) [1]. Nevertheless, the industrial processes are tailored to recover only valuable metals from e-waste. In general, when talking about e-waste, valuable metals are concentrated mainly on PCBs (printed circuit boards). The metals found in and on PCBs can be classified into five main groups, namely, base metals (BMs), precious metals (PMs), platinum group metals (PGMs), metals of concern (MCs, hazardous), and rare earth elements (REEs) [2,3].

- $\quad$ Base metals (BMs): $\mathrm{Cu}, \mathrm{Al}, \mathrm{Ni}, \mathrm{Sn}, \mathrm{Zn}$, and Fe;

- Precious metals (PMs): $\mathrm{Au}, \mathrm{Ag}, \mathrm{Pd}, \mathrm{Pt}, \mathrm{Rh}, \mathrm{Ir}$, and $\mathrm{Ru}$;

- Metals of concern (MCs, hazardous): $\mathrm{Hg}, \mathrm{Be}, \mathrm{In}, \mathrm{Pb}, \mathrm{Cd}, \mathrm{As}$, and Sb; 
- $\quad$ Scarce elements (REEs): Te, Ga, Se, Ta, and Ge.

The general pyro-metallurgical recycling process of PCBs (see Figure 1) is based on the combustion of the organic constituents of the material mix fed into the furnace and using the energy of this exothermic reaction to melt the other constituents. Therefore, depending on the desired process and the PCB content in the feed mix, the organic content is used either to substitute fossil energy (organic content $\leq 20 \mathrm{wt}$. \%. of the feed mix) or to run the entire process autothermal (organic content $>20 \mathrm{wt}$. $\%$. of the feed mix). Thus, an off gas containing combusted organics, flame retardants (bromide and chloride compounds), and parts of the zinc as oxide is produced. Currently, processes are able to recover most of the base metals $(\mathrm{Cu}, \mathrm{Ni}, \mathrm{Sn})$, as well as the precious metals ( $\mathrm{Au}, \mathrm{Ag}, \mathrm{Pd}, \mathrm{Pt})$, contained within the input material in a metal phase at the bottom of the furnace. Above this metal phase, a slag phase will form, containing the ceramic compounds of the feed mix, such as aluminum oxide, silicon dioxide, and magnesium oxide, as well as oxidized metals such as iron and aluminum. Unfortunately, there is always some of the base metal alloy, which is entrapped as droplets inside the slag $(\sim 1-2 \mathrm{wt}$. \% of the slag). Within these entrapped droplets, some of the precious metals, as well as parts of lead and tin in their metallic state, are lost to the slag. Depending on the process, atmosphere, and slag chemistry, oxidic forms of lead and tin may also occur. The last group of elements, i.e., the scarce elements, are mainly bound in the slag. However, depending on the chemical reactions inside the furnace, halides may also be formed and lost to the off gas [4]. Although the recycling process is quite well developed and plenty of research was done in that field, the distribution of scarce elements is still not fully understood, and an efficient recovery method is yet to be developed.

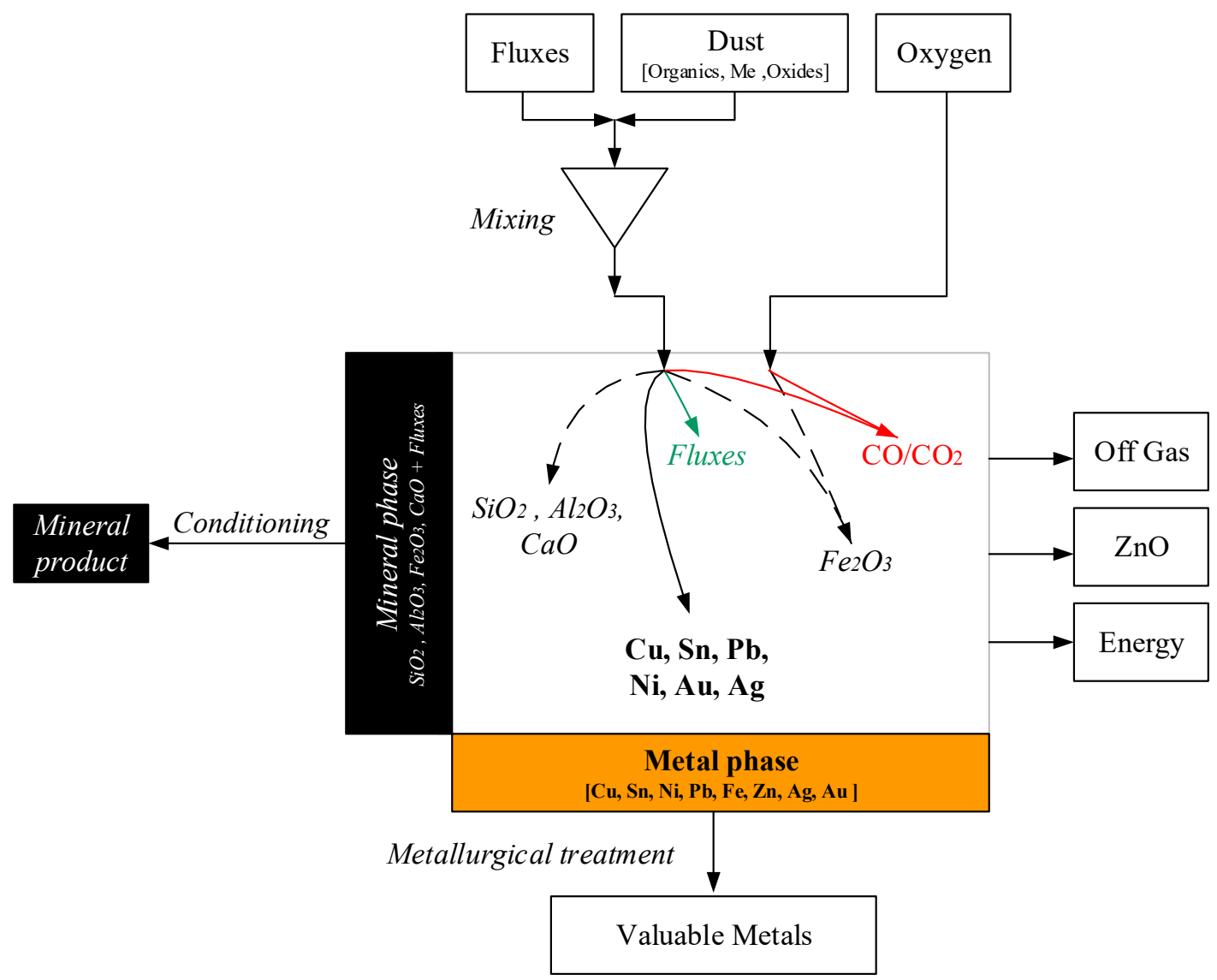

Figure 1. General schematic process of metal recycling from printed circuit board (PCB) scraps [5].

In order to reduce metal losses to the slag, facilitate their recovery, and possibly recover REEs, further investigation must be conducted. In this context, FACTSage ${ }^{\mathrm{TM}}$ (Thermafact/CRCT, 
Montreal, Canada and GTT-Technologies, Aachen, Germany) [6] offers one suitable opportunity to help understand the influence of slag chemistry on the viscosity of the slag, consequently enabling a detailed understanding and manipulation of the settling behavior to reduce these losses. A possible solution, which is investigated within this study, is the targeted concentration of metal parts, as well as scarce elements, in certain phases inside the slag, achieved through controlled cooling rates and slag chemistry. A positive concentration would facilitate further separation, collection, and subsequent recycling of these elements, enabling the recycling of scarce elements to become technically and economically feasible $[7,8]$.

With respect to a sustainable recycling strategy, a detailed understanding of the elemental distribution within the process, the reduction of metal losses to the slag, and the material properties of the product is essential. Therefore, the analysis of the present slag material in terms of formed structures depending on the cooling rate and the enrichment of metals in these structures is of great interest. Two main analysis methods were used in the present study, namely, SEM-based mineralogical analysis (MLA) and X-ray computed tomography (XCT).

SEM-based mineralogy (MLA) is a two-dimensional image analysis method based on scanning electron microscopy coupled with energy-dispersive X-ray spectroscopy $[9,10]$. It is proven to be a practical method for multidimensional characterization of various phases [11-13]. Using MLA allows for an integrated analysis of shape, size, and distribution of various phases within a specimen which can be a sample block, thin section, or a grain mount. By studying processes such as comminution or physical separation, process parameters can be directly related to product characteristics with respect to particle properties [14-17]. For example, the liberation of valuable phases with respect to grinding fineness, as well as the dominating fracture mechanisms, can be studied [18-20].

XCT enables a non-destructive three-dimensional characterization of specimens. As it is based on the X-ray attenuation of the volume elements (voxel), which is a function of the materials' average atomic number, wavelength, material density, and path length, voxels can have different chemical composition but similar attenuation coefficients [12]. Studying multiphase materials such as ores and slags can, thus, be challenging. Different approaches exist to face this problem. These are direct three-dimensional analysis of the chemical composition using X-ray fluorescence tomography [21,22] or the combination of two-dimensional analysis of the chemical composition with XCT [19,23-25].

The aim of the investigation is to identify if the slag could possibly represent an artificial resource or collecting agent for various valuable metals and rare earth elements. Based on the findings of this study, it is planned to develop an effective and efficient method for the downstream recycling process of the addressed elements. If it is possible to do so, a huge pyro-metallurgical process optimization potential is expected, as this resource can be influenced in various ways and no detailed knowledge is generated so far.

\section{Materials and Methods}

The slag, which was further investigated in this study, resulted from a previously conducted PCB melting experiment in a TBRC (top-blown rotary converter) of industrial scale ( $0.5 \mathrm{~m}^{3}$ melt volume) [5]. Within the experiment, $560 \mathrm{~kg}$ of finely ground PCBs were injected into a synthetic slag phase at $1300{ }^{\circ} \mathrm{C}$ starting temperature. The main elemental components of this injected material were $\mathrm{Cu}, \mathrm{Pb}$, $\mathrm{Zn}, \mathrm{Al}, \mathrm{Ni}$, and $\mathrm{Sn}$. For more details on the injected material, the reader is referred to Borowski et al. (2018) [5]. The general schematic experimental set-up is shown in Figure 2. 


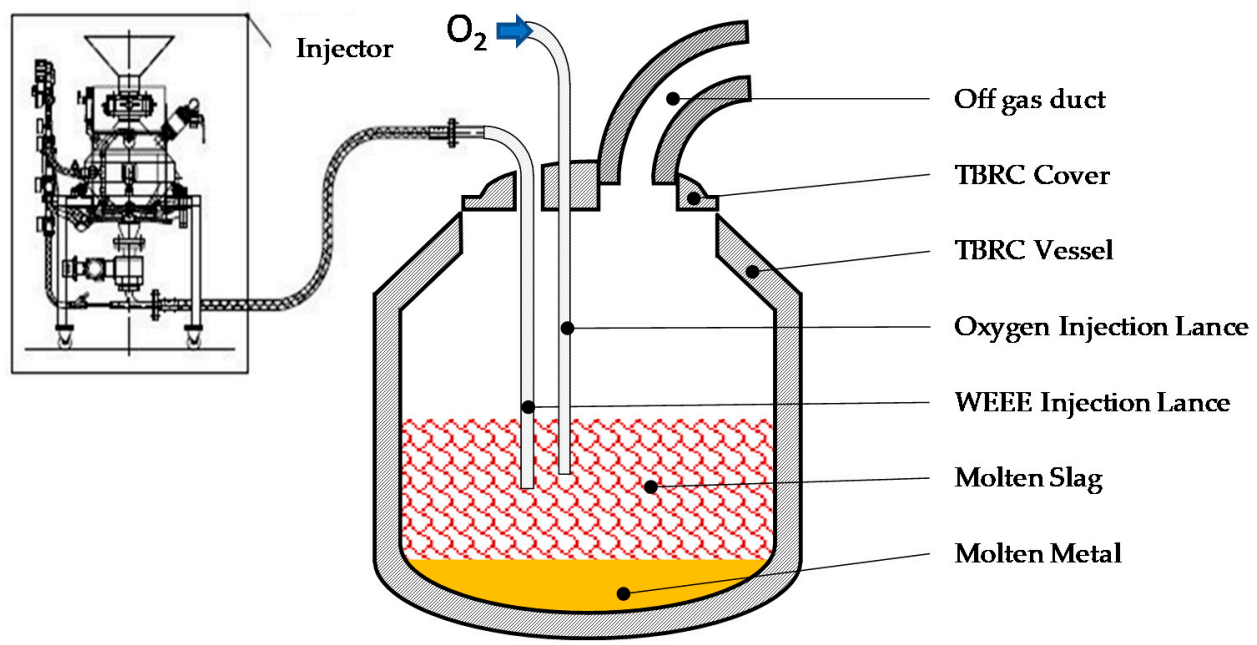

Figure 2. Schematic process of waste of electrical and electronic equipment (WEEE) powder injection into the slag phase.

The experiment was conducted with an initial molten slag bath formed by a composition of $\mathrm{SiO}_{2}$, $\mathrm{Al}_{2} \mathrm{O}_{3}$, and $\mathrm{CaO}$, chosen so that the lowest possible liquid temperature was achieved. The powder and fines were injected into the slag phase near the metal slag boundary through the injector (see Figure 3).
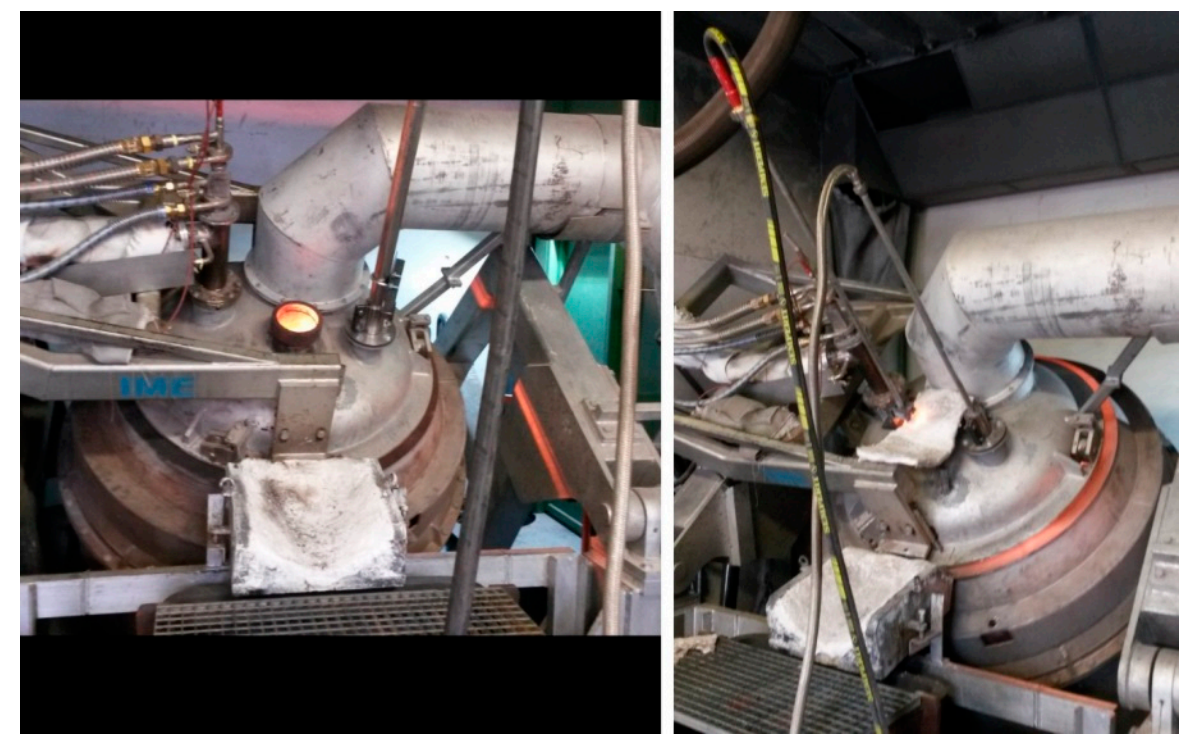

Figure 3. Top-blown rotary converter (TBRC) with lances for injecting WEEE powders and oxygen [5].

The mass flow of the injected WEEE powder was adjusted according to the calculated energy requirement for an autothermic melting process between $1350{ }^{\circ} \mathrm{C}$ and $1450{ }^{\circ} \mathrm{C}$ and was based on the calorific value of the organic content of approximately $30 \mathrm{wt}$. \% in the feed material. After $560 \mathrm{~kg}$ of material was continuously injected into the slag phase and $30 \mathrm{~min}$ of holding time elapsed, both slag and metal phases were tapped at $1450^{\circ} \mathrm{C}$ into a cold $\left(20^{\circ} \mathrm{C}\right)$ cast-iron ladle that was coated with a thin graphite layer (for more detailed information on the smelting process from which the investigated slag originates, see Borowski et al. (2018) [5]). In the ladle (see schematic in Figure 4), the metal was intended to settle at the bottom and to cool relatively quickly while the slag cooled down with different cooling rates from the outside to the center. At the ladle's cold side walls, in a very small zone 1 , very high cooling rates of approximately $>100 \mathrm{~K} / \mathrm{s}$ are realized. Here, the slag is intended to form an amorphous, glass-like structure, whereas, in the center of the ladle, in zone 3 , a mineral phase with crystalline structures is expected. Here, due to the solidified surrounding slag, the inner core is 
literally thermal insulated, and it features a very low cooling rate of approximately $<1 \mathrm{~K} / \mathrm{s}$. In between these two zones, the biggest zone 2 , with an "intermediate" cooling rate of approximately $5 \mathrm{~K} / \mathrm{s}$ (mean cooling rate of the entire zone), is formed.

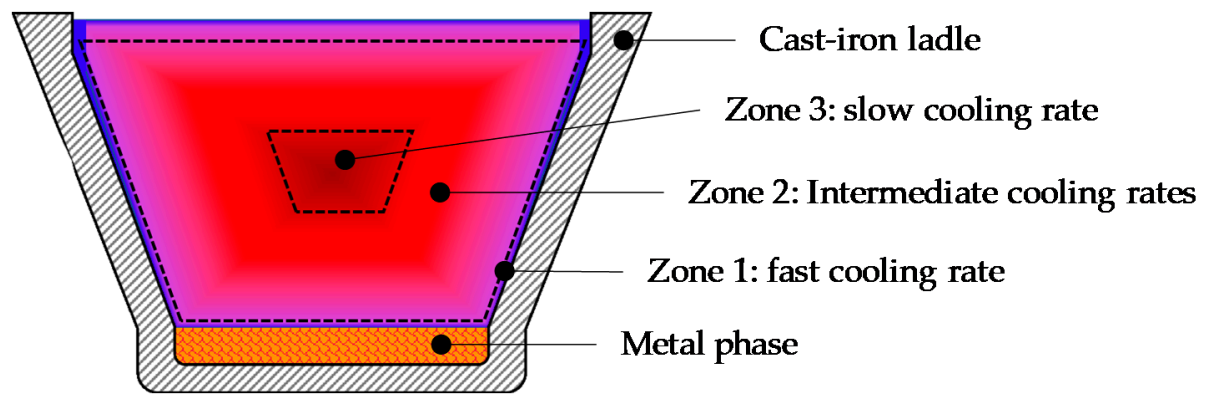

Figure 4. Schematic illustration of the slag ladle with expected cooling zones and cooling rates.

The main difference in metal concentration is expected between the inner (zone 3) and outer phase (zone 1) of maximal and minimal cooling rates. The slags of intermediate cooling rates (zone 2) will probably not differ much in terms of results from the inner phase (zone 3), as the cooling rates are too close to each other.

\subsection{X-Ray Computed Tomography}

In order to analyze the three-dimensional (3D) structure of the slag, the fragments of samples from the slag ladle (see Figure 4) of zone $1(\mathrm{H})$, zone $2(\mathrm{M})$, and zone $3(\mathrm{~S})$ were subsampled by drilling small cores ( $4 \mathrm{~mm}$ in diameter) from them. These cores were then glued on sample holders and scanned using X-ray computed tomography (XCT). The used XCT apparatus was a Zeiss Xradia 510 Versa X-ray microscope (Carl Zeiss AG, Oberkochen, Germany), which combines geometric and optical magnification for increased spatial resolution (Figure 5). The total magnification results from the product of geometric and optical magnification. Detailed information on XCT can be found, e.g., in a review article by Hanna and Ketcham (2017) [26].

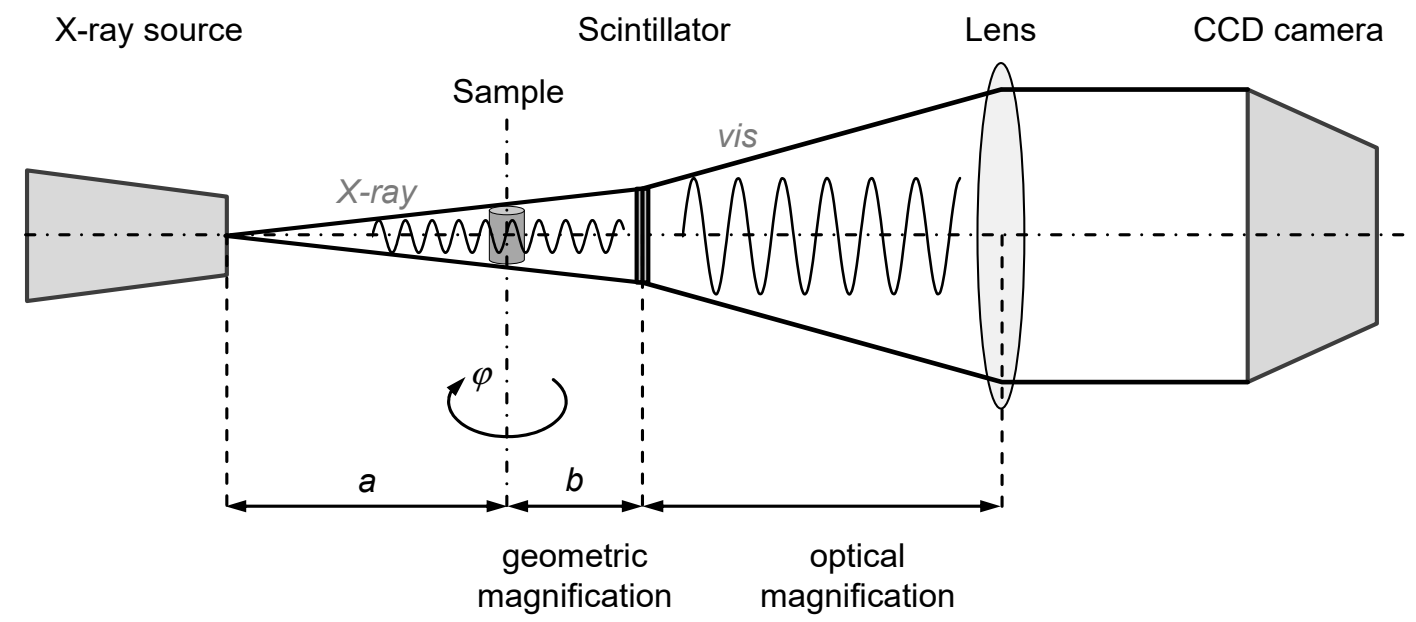

Figure 5. Working principle of an X-ray microscope combining geometric and optical magnification for increased spatial resolution.

XCT scans were done with two sets of parameters to analyze the whole core in a large field of view (FOV, $7.8 \mu \mathrm{m}$ voxel size) and to additionally get a high-resolution virtual subsample via an interior tomography using a small FOV $(2.77 \mu \mathrm{m}$ voxel size). The latter enabled a detailed view of small structures formed by the complex intergrowth of the different slag phases. The scan parameters are listed in Table 1. 
Table 1. Scan parameters from X-ray computed tomography (XCT) analysis.

\begin{tabular}{ccc}
\hline Scan & Total & Detail \\
\hline Source position $(\mathrm{mm})$ & -20 & -14 \\
Detector position $(\mathrm{mm})$ & 160 & 20 \\
Lens & $0.4 \times$ & $4 \times$ \\
Acceleration voltage $(\mathrm{keV})$ & 110 & 110 \\
Electrical power $(\mathrm{W})$ & 10 & 10 \\
Filter $($ Zeiss Standard) & $\mathrm{HE} 1$ & $\mathrm{HE} 1$ \\
Camera binning & 2 & 2 \\
Pixel size $(\mu \mathrm{m})$ & 7.8 & 2.77 \\
Number of projections & 801 & 2001 \\
Scan angle $\left(^{\circ}\right)$ & 360 & 360 \\
Scan time $(\mathrm{hh:mm})$ & $1: 18$ & $2: 23$ \\
\hline
\end{tabular}

The projection images were reconstructed using the scanner's proprietary software Scout\&Scan Reconstructor (Version 11.1.8043, Carl Zeiss AG, Oberkochen, Germany). The analysis of the final image stack was done with the software VGStudio MAX 3.3 (Volume Graphics GmbH, Heidelberg, Germany).

\subsection{Scanning Electron Microscopy-Based Mineralogical Analysis}

In preparation for the investigation via MLA, the samples were crushed and ground down to a particle size of $<500 \mu \mathrm{m}$. Subsequently, the material was screened into four different size fractions. Samples of these size fractions were analyzed separately by MLA. The preparation of the samples is shown in Figure 6.

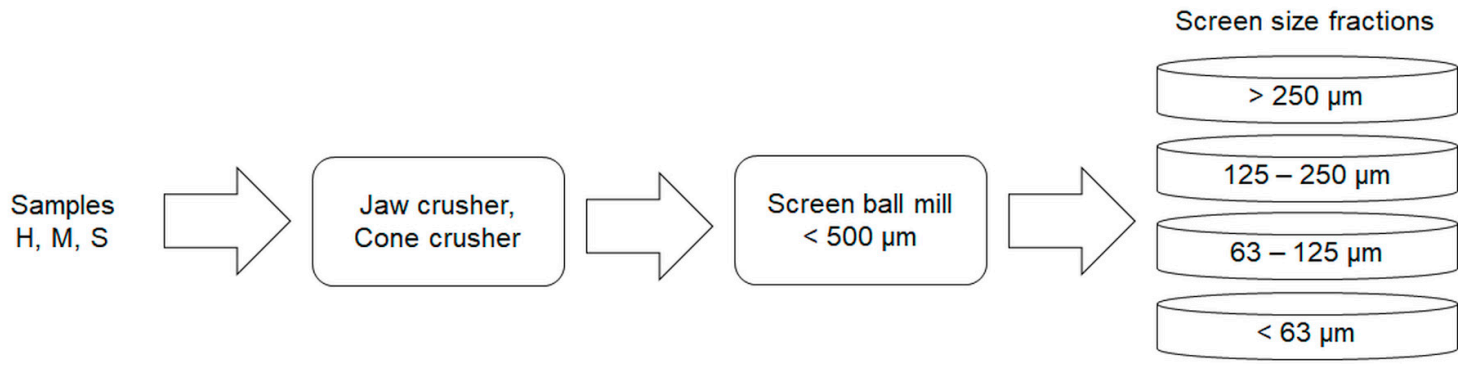

Figure 6. Preparation of samples H, M, and S for analyses via SEM-based image analyses; after a sequence of jaw and cone crushing, the material is milled down to an upper particle size of $500 \mu \mathrm{m}$. The material is then screened into four size fractions.

The samples were analyzed by means of a mineral liberation analyzer (MLA). Grain mounts of the particle samples were prepared by mixing $3 \mathrm{~g}$ of material with the same volume of graphite and epoxy resin. The grain mounts were polished and subsequently carbon-coated with a Leica (Baltec) MED 020 vacuum evaporator (Leica Microsystems, Wetzlar, Germany). The MLA consisted of an FEI Quanta 650F (Thermo Fisher Scientific, Waltham, MA, USA) field-emission SEM (FE-SEM) equipped with two Bruker Quantax X-Flash 5030 (Bruker, Billerica, MA, USA) energy-dispersive X-ray detectors (EDX). Identification of mineral grains by MLA involves backscattered electron (BSE) image segmentation and collection of EDX spectra of the particles and grains distinguished in GXMAP (grain-based X-ray mapping) mode. In this mode, EDX spectra of each particle are collected in a dense grid and further classified, using a list of mineral spectra collected by the user. The GXMAP measurement mode was applied to all samples [10]. Data processing and evaluation was done with the software package MLA Suite 3.1.4.686. The scan parameters for measurement are listed in Table 2. 
Table 2. Scan parameters from mineral liberation analyzer (MLA) analysis. BSE—backscattered electron.

\begin{tabular}{cc}
\hline GXMAP Parameters & Total \\
\hline Voltage $(\mathrm{kV})$ & 25 \\
Probe current $(\mathrm{nA})$ & 10 \\
Horizontal field width $(\mu \mathrm{m})$ & 1000 \\
BSE calibration & 253 \\
Resolution $(\mathrm{px})$ & $500 \times 500$ \\
Pixel size $(\mu \mathrm{m} / \mathrm{px})$ & 2 \\
GXMAP trigger & 25 \\
Step size $(\mathrm{px})$ & 6 \\
Minimum grain size $(\mathrm{px})$ & 4 \\
\hline
\end{tabular}

\section{Results}

After cooling the tapped slag, the discarded slag showed that the produced metal settled properly (see Figure 7B) at the bottom of the ladle and could, as intended, be easily separated from the slag. The slag, as shown in Figure 7, also showed the expected structures. The outermost slag shell was amorphous and glass-like and looked like a black-green basalt glass. The slag of zone 2 showed no amorphous phases. Here, small metallic inclusions were very easily visible. In the innermost zone 3 , after $24 \mathrm{~h}$ of cooling (approximately $80^{\circ} \mathrm{C}$ ), the slag mostly showed the same structure to that in the intermediate zone, but with a more pronounced crystallinity.

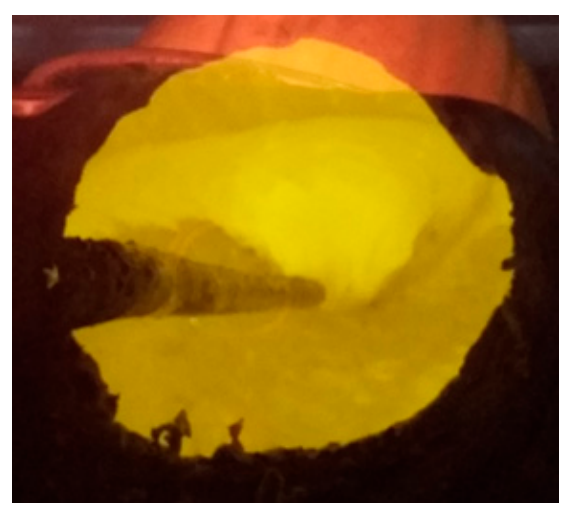

(A)

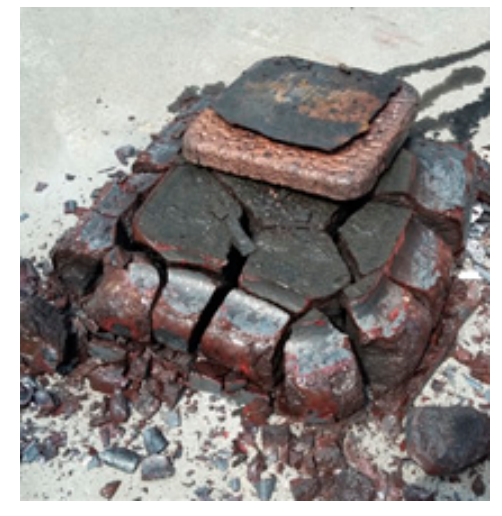

(B)

Figure 7. (A) Molten slag phase inside the TBRC during the melting process; (B) cooled slag and metal block [5].

After cooling and crushing, the slag was subsequently analyzed. Therefore, several samples from different positions inside the ladle were taken, and the mean composition of the slag was determined. Table 3 shows the values for the main components of the slag and most important components in terms of viscosity and cooling rate.

Table 3. Average composition and liquid temperature of the slag.

\begin{tabular}{cccccccc}
\hline Slag & $\mathrm{SiO}_{2}$ & $\mathrm{Al}_{2} \mathrm{O}_{3}$ & $\mathrm{CaO}$ & $\mathrm{Fe}_{\mathbf{x}} \mathrm{O}_{\mathbf{y}}$ & $\mathrm{CuO}$ & $\mathrm{PbO}$ & $T_{\text {liq }}\left({ }^{\circ} \mathrm{C}\right)$ \\
\hline wt. $\%$ & 36 & 31.6 & 19.2 & 22.0 & 5.4 & 0.5 & $1350-1400$ \\
\hline
\end{tabular}

The slag material used in further investigations was individually sampled from different positions of the three cooling zones. One sample $(\mathrm{H})$ originated from zone 1 , the outer region of the ladle with a high cooling rate. The two other samples ( $\mathrm{M}$ and $\mathrm{S}$ ) were sampled from more central areas of the slag inside the ladle, whereby sample $M$ was taken from zone 2 and sample $S$ was taken from the most 
central zone 3. All taken samples from the designated cooling zones were analyzed by X-ray computer tomography (XCT) and SEM-based image analysis (MLA).

\subsection{Results of Computer Tomography}

Results of XCT analysis are given in Figure 8. In the top row of Figure 8, the projection images of the three different samples $\mathrm{H}, \mathrm{M}$, and $\mathrm{S}$ are shown to give an overview of the structure within the measured volume. The second row shows the cross-sections through the scanned volumes. The red lines visible in the projection images indicate the position of these cross-sections within the volume. The grayscale represents the X-ray attenuation, which is a function of the materials' average atomic number, the wavelength of the X-ray, the material density, and the material thickness. Increased absorption by a region results in a brighter appearance in the image, with pores appearing as dark regions.
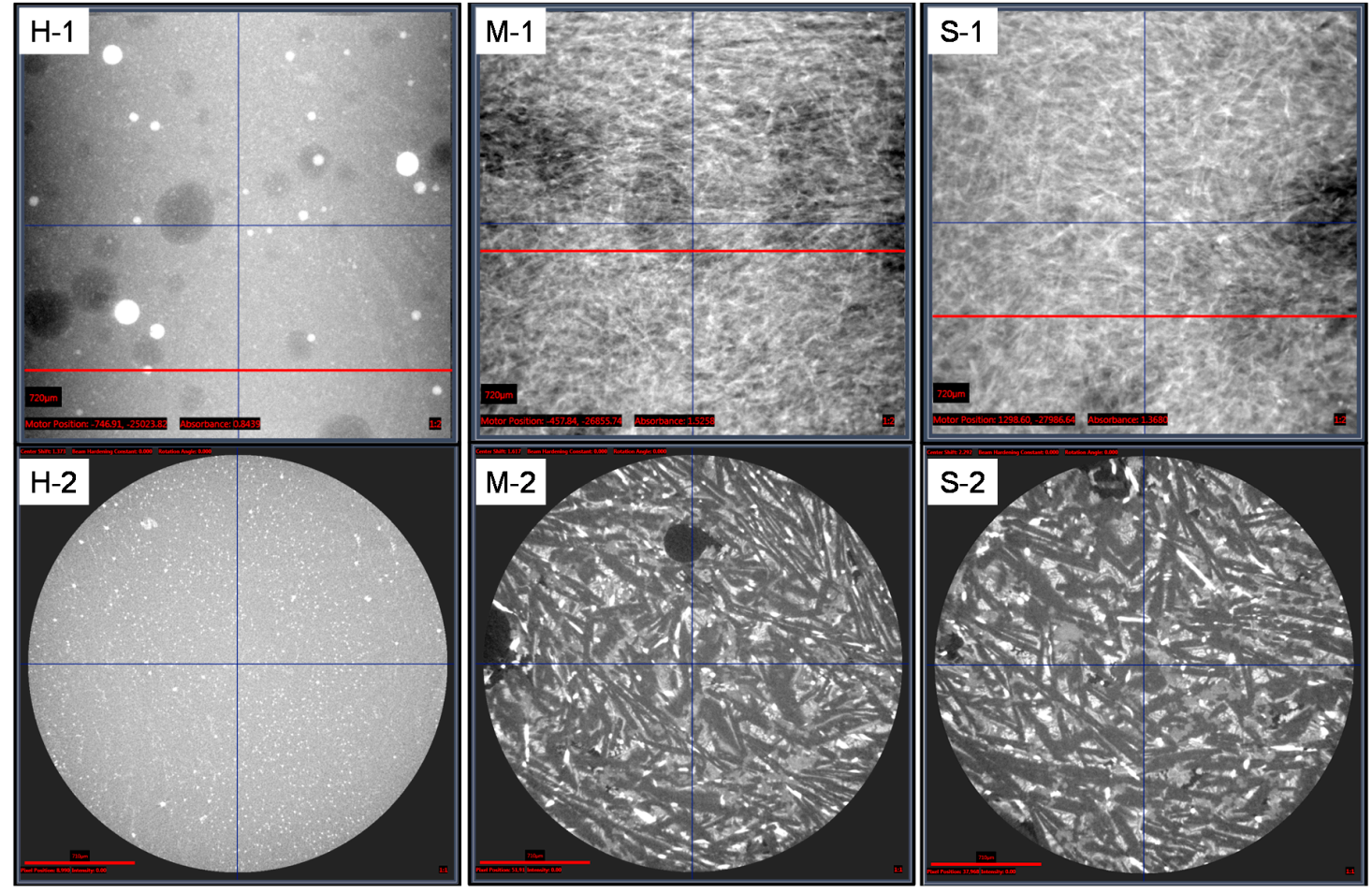

Figure 8. Results from XCT of samples $\mathrm{H}, \mathrm{M}$, and $\mathrm{S}$. Top row: projection images of the analyzed volumes giving an overview of the structures and the size scale; bottom row: reconstructed cross-sections from the position of the red line in the projection images.

The morphological analysis of the metal-rich phases (bright regions in the images of Figure 8) showed that they appear as plate-like to needle-like shapes. Their smallest dimension was often below $100 \mu \mathrm{m}$. Mechanical liberation by comminution will, therefore, be challenging, and it requires grinding at least down to an upper particle size of roughly the above given number. The visualization of the metal-rich phases shown in Figure 9 gives an idea of their morphology.

Comparing the projection image of sample $\mathrm{H}$ and a slice through the reconstructed volume shown in the first row of Figure 8 demonstrates a problem related to two-dimensional analysis. Pores and spherical strong absorbing phases are clearly visible in the projection image but lacking in the chosen section. Therefore, the strong absorbing phases were analyzed in order to measure their size distribution and volume percentage. This helped to estimate whether or not results from subsequent two-dimensional analysis may be misleading. Figure 10 shows a rendering from the inclusion analysis. Spherical inclusions up to approximately $700 \mu \mathrm{m}$ in diameter were found. These inclusions only 
accounted for $\sim 0.4 \%$ of the sample volume and can, therefore, be neglected with respect to the processing of the slag.

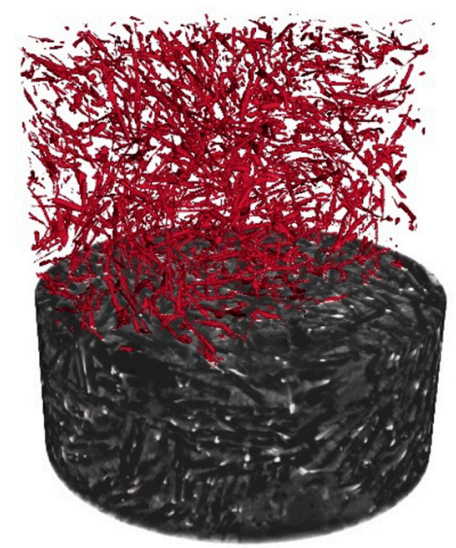

Figure 9. Visualization of the morphology of the metal-rich phases of sample S.

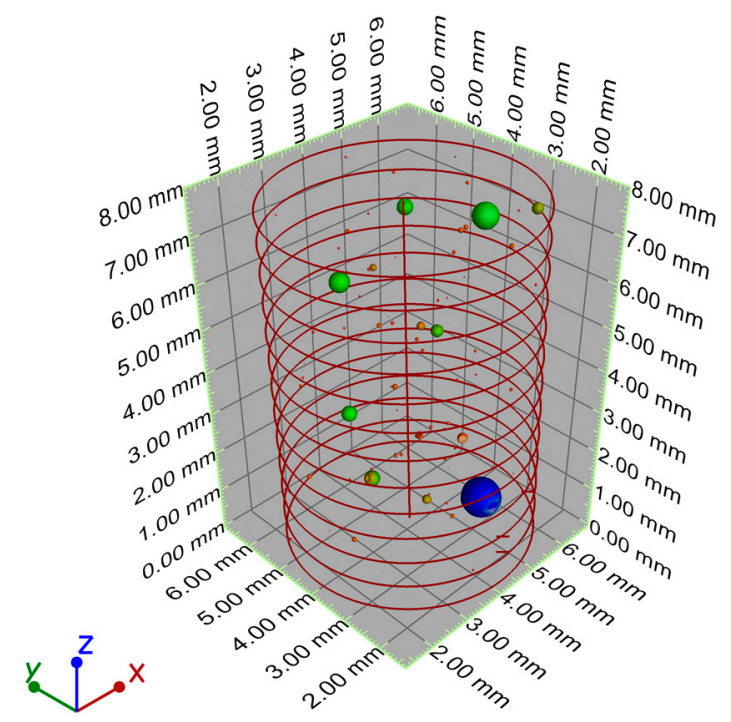

Figure 10. Rendering of spherical metallic inclusions contained in sample $\mathrm{H}$.

\subsection{Results of SEM-Based Mineralogical Analysis}

In addition to the analyses via XCT, the material was analyzed with MLA according to Section 2.2. Based on these MLA observations, it was shown that the particles in sample $\mathrm{H}$ had a different habitus than the particles of the samples M and S, which is in good agreement with the results of the XCT analysis. The $\mathrm{Cu}$-rich phases displayed a variety of shapes, i.e., forming melting droplets and drop aggregates, veins, or dendritic crystals. Those various $\mathrm{Cu}$-containing phases were present in all samples and had to be compared based on concentration, content of $\mathrm{Cu}$, structure, and recoverability by various methods. The main reason for the previous grinding of the sample to $<500 \mu \mathrm{m}$ is explainable by the anisotropic structure of the investigated sample. Another reason is the available size for a typical grain mount, where bigger particles would cause an insufficient representativity and, at the same time, would lead to a disproportional measurement effort. Furthermore, it would help get first insight into the liberation behavior of the valuable material.

An overview of the particles analyzed via MLA of the different samples is shown in Figure 11. 


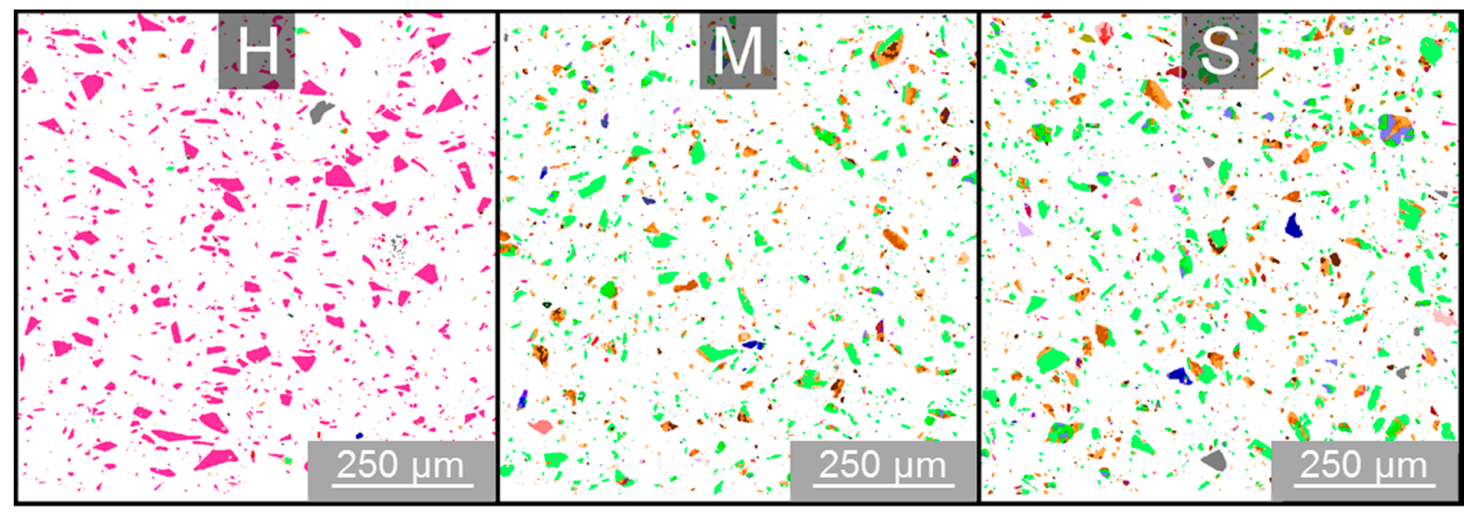

Figure 11. Overview of the three slag samples $H, M$, and S: MLA false color images display the difference between sample $\mathrm{H}$ and samples $\mathrm{M}$ and $\mathrm{S}$.

From the false color images in Figure 11, it can be seen that the elemental content and structure of the particles of sample $\mathrm{H}$ were significantly different from samples $\mathrm{M}$ and $\mathrm{S}$. The samples $\mathrm{M}$ and $\mathrm{S}$ can be considered as similar regarding particle composition and properties.

The mass recovery of the size fractions gives an overview of the different breakage behavior for the various slag samples. As displayed in Table 4, the mass recoveries for $\mathrm{H}, \mathrm{M}$, and $\mathrm{S}$ showed significant differences. The fine fraction $<63 \mu \mathrm{m}$ increased from $\mathrm{H}$ to $\mathrm{M}$ and to $\mathrm{S}$. The coarsest fraction $>250 \mu \mathrm{m}$ showed the inverse trend.

Table 4. Mass recovery of the different size fractions of the samples $\mathrm{H}, \mathrm{M}$ and S.

\begin{tabular}{cccc}
\hline $\begin{array}{c}\text { Size Fraction } \\
(\boldsymbol{\mu m})\end{array}$ & $\begin{array}{c}\mathbf{H} \\
\mathbf{( \% )}\end{array}$ & $\begin{array}{c}\text { M } \\
(\mathbf{\%})\end{array}$ & $\begin{array}{c}\text { S } \\
(\mathbf{\%})\end{array}$ \\
\hline$>250$ & 31.9 & 30.0 & 15.2 \\
$125-250$ & 30.3 & 22.5 & 23.2 \\
$63-125$ & 18.1 & 18.7 & 22.8 \\
$<63$ & 19.8 & 28.7 & 38.8 \\
\hline
\end{tabular}

The breakage characteristics of the slag seemed to change between the outer and the inner region. More and more fines appeared below $63 \mu \mathrm{m}$. One explanation could be the finer intergrown structure of the samples from the inner regions, compared to the mainly homogeneous structure of sample $\mathrm{H}$. Furthermore, the decreasing brittle character of the inner sample led to more abrasion. Nevertheless, the results showed the effect on the breakage characteristics of the cooling rate, which could, therefore, be adjusted to a certain desired behavior.

As $\mathrm{Cu}$ was the main valuable metal with significant content within the investigated slag samples, various aspects regarding $\mathrm{Cu}$ are discussed in the following sections. It has to be stated that $\mathrm{Cu}$ was present in two different forms in the slag material: $\mathrm{Cu}$-bearing slag phase (Cu-rich) and pure metal (Cu-metal). This statement is evaluated in more detail in the following section with various representations focusing on this aspect. The total content of $\mathrm{Cu}$ in the three different samples is shown in Table 5. The $\mathrm{Cu}$ content is shown for the different size fractions, and an average value is indicated.

Table 5 illustrates that $\mathrm{M}$ and $\mathrm{S}$ showed a much higher $\mathrm{Cu}$ content than $\mathrm{H}$. The $\mathrm{Cu}$ content of $\mathrm{H}$ was in the range of $3 \mathrm{wt}$. \%, whereas $\mathrm{M}$ and S showed approximately $18 \mathrm{wt}$. \% Cu. Furthermore, there was no enrichment of $\mathrm{Cu}$ in certain size fractions, resulting in a particle size-independent content. Additionally, the $\mathrm{Cu}$ present as pure metal droplets is shown in Table 6. The portion of $\mathrm{Cu}$ present as metal represents the amount of $\mathrm{Cu}$ that is recyclable in a certain way. The rest of $\mathrm{Cu}$ that is present as a slag phase is very likely lost or difficult to gain for a further recycling process. Fortunately, the content of $\mathrm{Cu}$-metal increased from $\mathrm{H}$ over $\mathrm{M}$ to S. Sample $\mathrm{S}$ showed the highest content of $\mathrm{Cu}$-metal with again no enrichment in a specific size class being visible according to Table 6. 
Table 5. Total $\mathrm{Cu}$ content of the different size fractions and average value of samples $\mathrm{H}, \mathrm{M}$, and S.

\begin{tabular}{cccc}
\hline $\begin{array}{c}\text { Size Fraction } \\
(\boldsymbol{\mu m})\end{array}$ & $\begin{array}{c}\mathbf{H} \\
\mathbf{( \% )}\end{array}$ & $\begin{array}{c}\mathbf{M} \\
\mathbf{( \% )}\end{array}$ & $\begin{array}{c}\mathbf{S} \\
\mathbf{( \% )}\end{array}$ \\
\hline$>250$ & 2.9 & 17.9 & 18.1 \\
$125-250$ & 2.9 & 18.7 & 18.3 \\
$63-125$ & 3.1 & 18.7 & 18.4 \\
$<63$ & 3.5 & 18.4 & 17.7 \\
Average & 3.1 & 18.4 & 18.1 \\
\hline
\end{tabular}

Table 6. Cu-metal content of the different size fractions and average value of the samples $\mathrm{H}, \mathrm{M}$, and S.

\begin{tabular}{cccc}
\hline $\begin{array}{c}\text { Size Fraction } \\
(\boldsymbol{\mu m})\end{array}$ & $\begin{array}{c}\mathbf{H} \\
\mathbf{( \% )}\end{array}$ & $\begin{array}{c}\mathbf{M} \\
\mathbf{( \% )}\end{array}$ & $\begin{array}{c}\mathbf{S} \\
\mathbf{( \% )}\end{array}$ \\
\hline$>250$ & 0.4 & 7.2 & 8.7 \\
$125-250$ & 0.4 & 7.8 & 8.7 \\
$63-125$ & 0.5 & 8.0 & 8.6 \\
$<63$ & 0.6 & 7.7 & 8.4 \\
Average & 0.4 & 7.7 & 8.5 \\
\hline
\end{tabular}

Another aspect of interest concerning a potential recycling process for $\mathrm{Cu}$ is the size of these metal droplets within the sample. Therefore, their size distribution is shown in Figure 12. The size distributions of $\mathrm{M}$ and $\mathrm{S}$ were in the same range, while $\mathrm{H}$ showed a much finer size distribution. Nevertheless, all three size distributions were in a rather fine range for a potential mechanical separation process. Furthermore, it needs to be stressed that the required liberation size is around 1/10 of the grain size assuming random fracture [27]. Slags are known to be close to a pure random fracture due to their brittle behavior caused by amorphous phases and rough interfaces [18]. Upgrading Cu-rich phases by mechanical separation processes will, thus, be challenging with respect to the required liberation size.

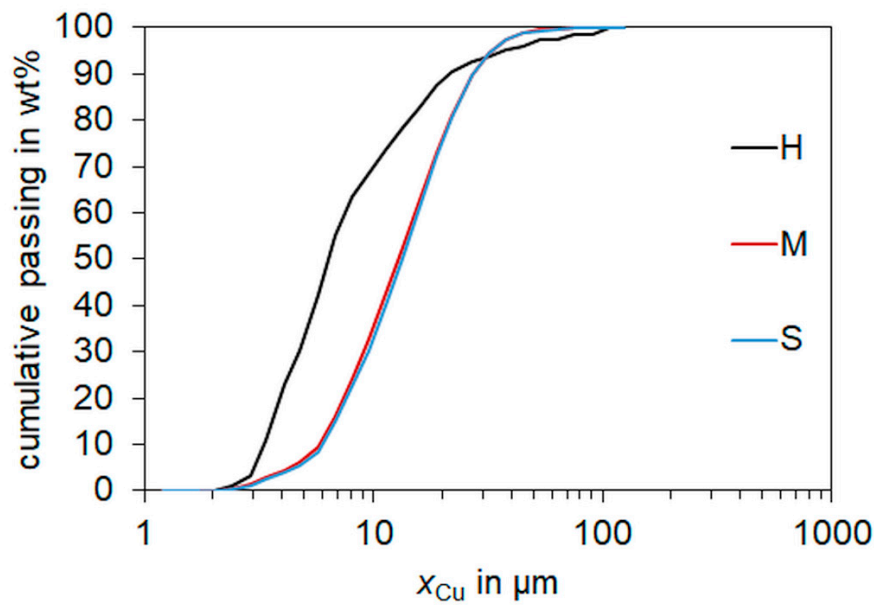

Figure 12. Cu-metal grain size distribution of the three different sampling areas.

A further important characteristic is the shape of the $\mathrm{Cu}$-metal droplets within the different slag structures. From the results of XCT analyses of Section 3.1, it was already concluded that the structure of sample $H$ was different from that of samples $M$ and $S$. For further investigations, representative examples of the particles analyzed by MLA for sample H (see Figure 13) and for samples M and S (Figure 14) are analyzed in more detail. The shape of the $\mathrm{Cu}$ grains in sample $\mathrm{H}$ showed a circular shape. In connection with 3D analysis via XCT, it can be concluded that these Cu-metals in sample $\mathrm{H}$ were spheres formed by droplets. These spheres (brown color in Figure 13) showed no connection to the surrounding amorphous phase. The amorphous phase in sample H shown in Figure 13 is 
represented by the pink color, and it consisted mainly of the elements $\mathrm{Ca}(\sim 12 \%), \mathrm{Al}(\sim 15 \%), \mathrm{Fe}(\sim 2 \%)$, $\mathrm{Cu}(\sim 2 \%), \mathrm{Si}(\sim 27 \%)$, and $\mathrm{O}(\sim 40 \%)$.

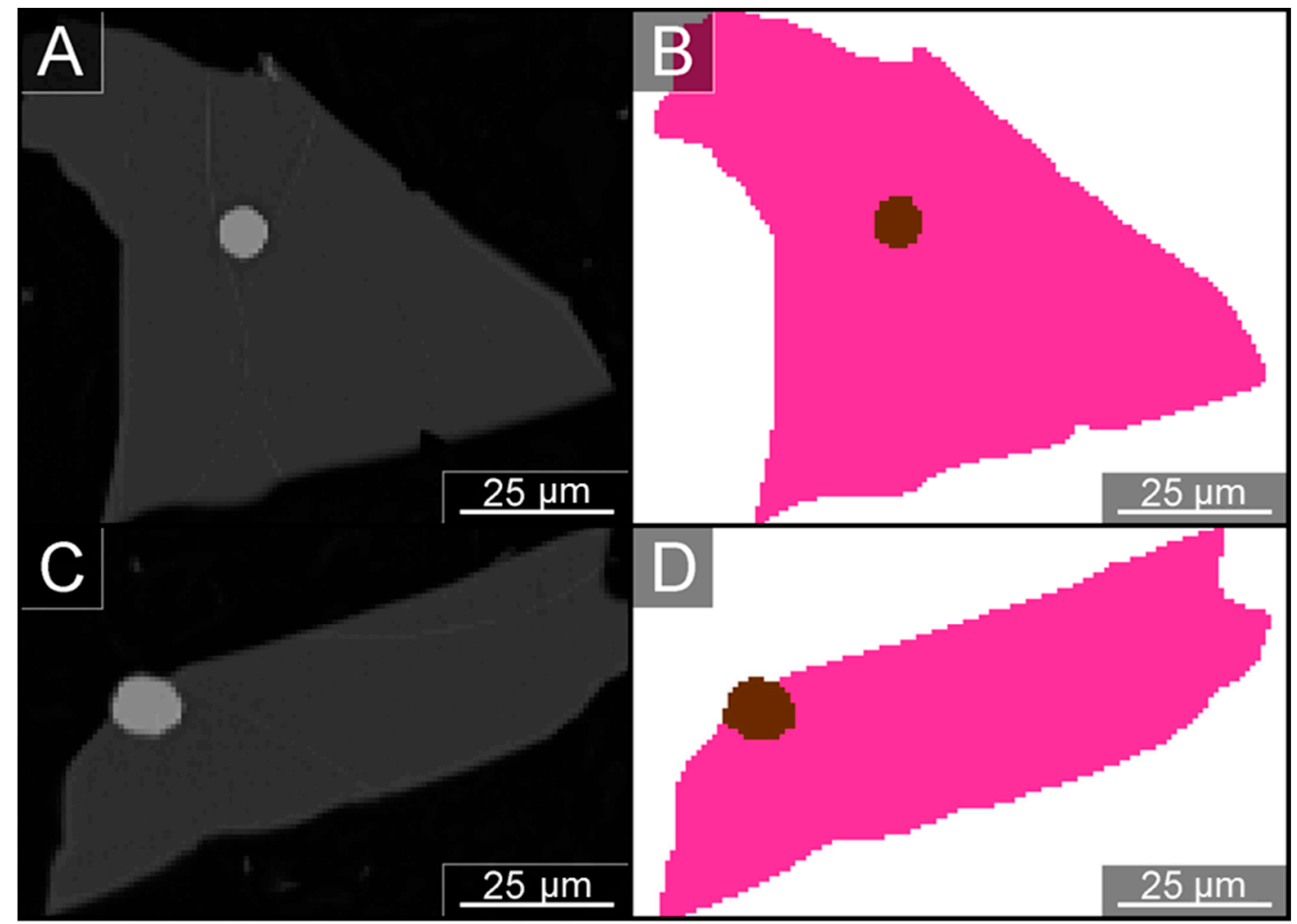

Figure 13. Typical particles with copper inclusion of sample H: (left, A and C) grayscales from BSE images; (right, B and D) associated false color images indicating different phases: pink (amorphous $\mathrm{Al}$ slag phase), brown (Cu-metal).

These metal droplets in sample $\mathrm{H}$ originated from the turbulent mixing during the smelting process. The metal droplets were transported to the slag phase. The cooling rate in this range was high enough to inhibit settling of the $\mathrm{Cu}$ droplets back to the metal phase at the bottom of the furnace. This theory is further confirmed as the $\mathrm{Cu}$ droplets showed a sharp boundary to the surrounding slag phases of sample $\mathrm{H}$. A very different observation can be made in samples $\mathrm{M}$ and $\mathrm{S}$ displayed in Figure 14. In these samples, particles containing $\mathrm{Cu}$ comprised $\mathrm{Cu}$-metal droplet aggregates in association with $\mathrm{Cu}$-bearing slag phases.

There are two main areas visible in the false color image of Figure 14. Firstly, there is a more or less homogeneous, needle-like green region (the dark phase in Figure 8 and on the left side of Figure $14 \mathrm{~A}, \mathrm{C})$. The second main area is more heterogeneous, marked by brownish colors showing a variety of different phases. The $\mathrm{Cu}$-rich phase consisted of a matrix phase consisting of phases $\mathrm{b}$ and c, a dendritic structure (phase d), and the Cu-metal visible as round droplets (see phases in Table 7). The main elemental contents of these dominant phases are shown Table 7. The Cu-metal phase (phase e in Table 7) always showed an agglomeration of spherical droplets within the Cu-rich matrix phases $(\mathrm{b}$ and $\mathrm{c})$. The phase $\mathrm{d}$ indicated a dendritic structure with a quite high $\mathrm{Cu}$ content of approximately $49 \%$. In the whole sample ( $\mathrm{M}$ and $\mathrm{S}$ ), the Al-rich ( $\mathrm{a}$ in Table 7 ) phase summed up to approximately $50 \%$, the $\mathrm{Cu}$-rich phase summed up to approximately $35 \%$ (sum of phases $\mathrm{b}-\mathrm{d}$ ), and the Cu-metal represented $9 \%$. 


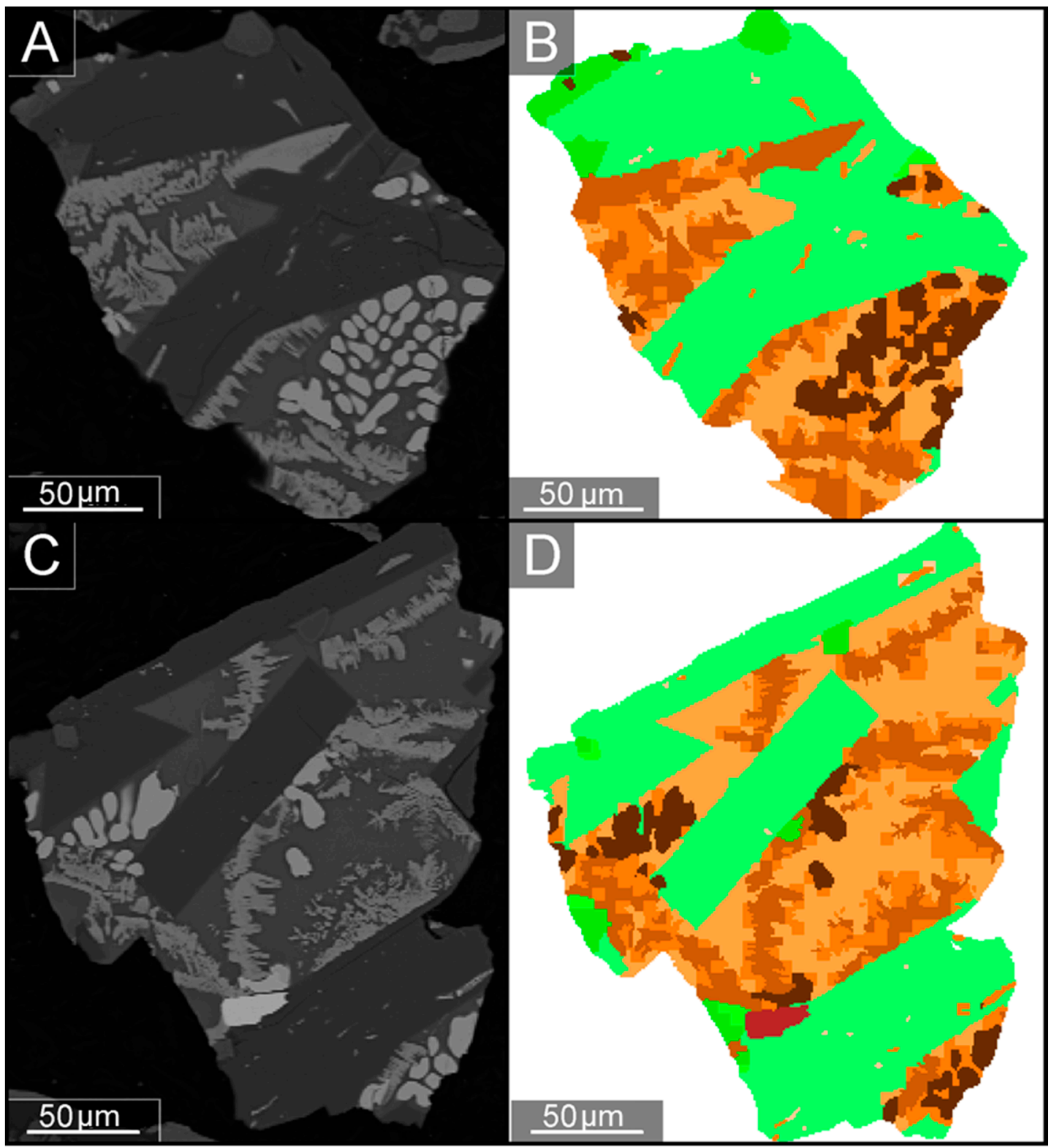

Figure 14. Typical particles with different phases of the samples $M$ and S: (left, $\mathbf{A}$ and $\mathbf{C}$ ) grayscales from BSE images; (right, B and D) associated false color images indicating different phases: green (Al-rich slag phase), brownish colors (Cu-rich phases) (see Table 7).

Table 7. Main elemental content of the dominant phases of samples M and S.

\begin{tabular}{|c|c|c|c|c|c|c|c|}
\hline $\begin{array}{c}\text { Phase } \\
\text { (see Figure 14) }\end{array}$ & $\begin{array}{l}\mathrm{Cu} \\
(\%)\end{array}$ & $\begin{array}{l}\mathrm{Fe} \\
(\%)\end{array}$ & $\begin{array}{l}\mathrm{Al} \\
(\%)\end{array}$ & $\begin{array}{l}\mathrm{Ca} \\
(\%)\end{array}$ & $\begin{array}{l}\mathrm{Pb} \\
(\%)\end{array}$ & $\begin{array}{l}\mathrm{Si} \\
(\%)\end{array}$ & $\begin{array}{c}\mathrm{O} \\
(\%)\end{array}$ \\
\hline a & $<1$ & $<1$ & 24 & 15 & 0 & 20 & 39 \\
\hline$b$ & 15 & $<1$ & 11 & 4 & 3 & 23 & 37 \\
\hline c & 17 & 4 & 12 & 3 & 3 & 23 & 34 \\
\hline$d$ & 49 & 19 & 12 & 0 & 0 & 0 & 16 \\
\hline e & 100 & - & - & - & - & - & - \\
\hline
\end{tabular}


The Cu-metal droplets always appeared within the $\mathrm{Cu}$-rich matrix (b and c). This fact supports the hypothesis of the occurrence of a transportation process in connection with a formation of $\mathrm{Cu}$-rich dendrites (phase d) and an agglomeration of $\mathrm{Cu}$ droplets (phase e). These processes are in fact a function of the cooling rate. In conjunction with the increasing proportion of Cu-metal droplets with more distance to the outer region of the slag (see Table 6), the cooling rate seemed to influence the appearance of the $\mathrm{Cu}$-metal droplets and the characteristics of the surrounding phases.

The deportment of the element $\mathrm{Cu}$, which is the major valuable element in the present material, into the different phases of the investigated slag structures is an important factor for the assessment of its recyclability. Figure 15 shows the deportment of $\mathrm{Cu}$ into the different main phases of the three samples $\mathrm{H}, \mathrm{M}$, and $\mathrm{S}$.

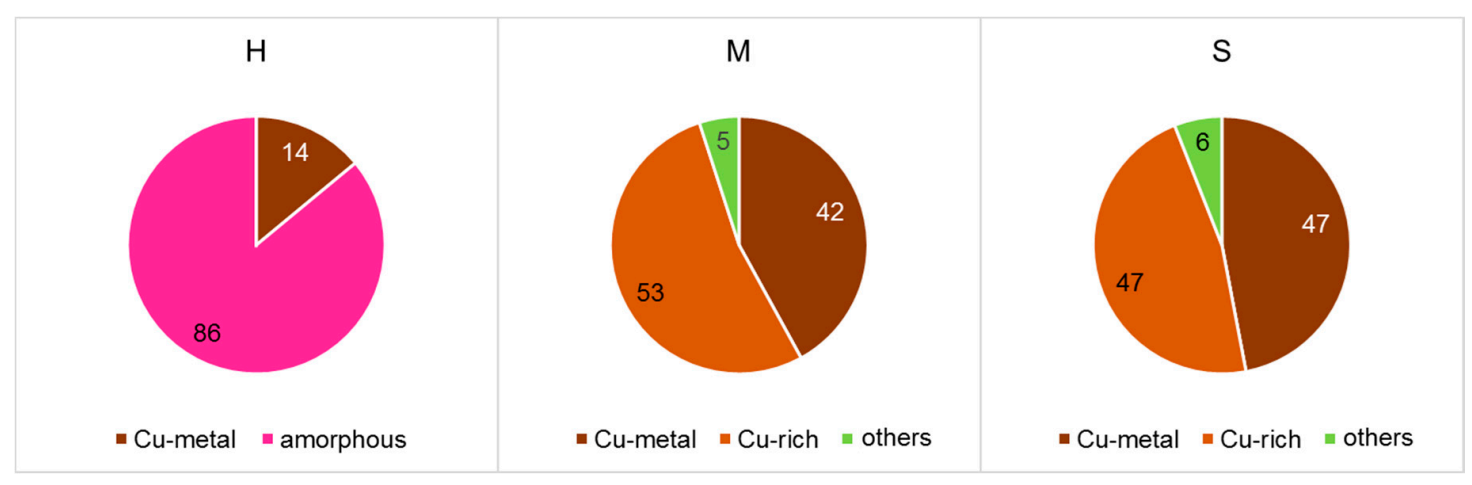

Figure 15. Deportment of $\mathrm{Cu}$ as a percentage in the three different samples $(\mathrm{H}, \mathrm{M}$, and $\mathrm{S})$ between the different main phases: $\mathrm{Cu}$-metal, $\mathrm{Cu}$-rich, and amorphous.

For sample $\mathrm{H}$, the majority of $\mathrm{Cu}$ was found in the amorphous phase. Only $14 \%$ of the total $\mathrm{Cu}$ content within this sample appeared as the metallic phase. This ratio underlines the low potential for the recycling of the material of this outer zone $(\mathrm{H})$. In contrast to that, the ratios for sample $\mathrm{M}$ and $S$ were much more promising with regard to potential recycling, e.g., via mechanical separation processes. For these samples, the amount of $\mathrm{Cu}$ present as the metallic phase was much higher $(42 \%$ and 47\%, respectively). The Cu-rich phase in Figure 15 summarizes the phases b, c, and d from Table 7.

For a potential mechanical processing of the material to enrich the $\mathrm{Cu}$-metal phase via separation processes, the liberation of this phase is of major interest. Therefore, in Figure 16, the particle-based information from MLA is binned into property classes of particle size $\left(x_{\mathrm{P}}\right.$ in $\left.\mu \mathrm{m}\right)$ and liberation of the $\mathrm{Cu}$-metal phase ( $L$ in vol. \%, indicating the proportion of $\mathrm{Cu}$-metal in a particle). In the individual bins of $x_{\mathrm{P}}$ and $L$, the theoretical recovery of $\mathrm{Cu}$-metal phase $\left(r_{\mathrm{Cu} \text {-metal }}\right)$ is indicated by number and the color scale. The focus of these considerations is only on samples M and S, due to the low potential of sample $\mathrm{H}$ for further recycling steps.

The recovery values $\left(r_{\mathrm{Cu} \text {-metal }}\right)$ of the $\mathrm{Cu}$-metal phase in Figure 16 summed up to $100 \%$ for each sample. According to Figure 16, the distribution in the different $x_{\mathrm{P}}$ and L classes of the Cu-metal phase was more or less the same for samples $M$ and $S$ with only minor differences. The majority of the $\mathrm{Cu}$-metal was in the range of $40 \mu \mathrm{m}$ to $320 \mu \mathrm{m}$, showing a rather low liberation $(\leq 50 \%)$. This material needs to be further liberated by additional comminution steps. These comminution steps have to be controlled (e.g., via combination with a suitable classification process) to avoid an overgrinding of the $\mathrm{Cu}$-metal phase, not to increase the amount in the lower particle size range. Already more than $20 \%$ of the Cu-metal is in a range below $40 \mu \mathrm{m}$. Despite some fractions showing a satisfying liberation $(L>70 \%)$, this relatively low size range is already challenging for conventional mechanical separation processes (e.g., density separation via shaking tables). 


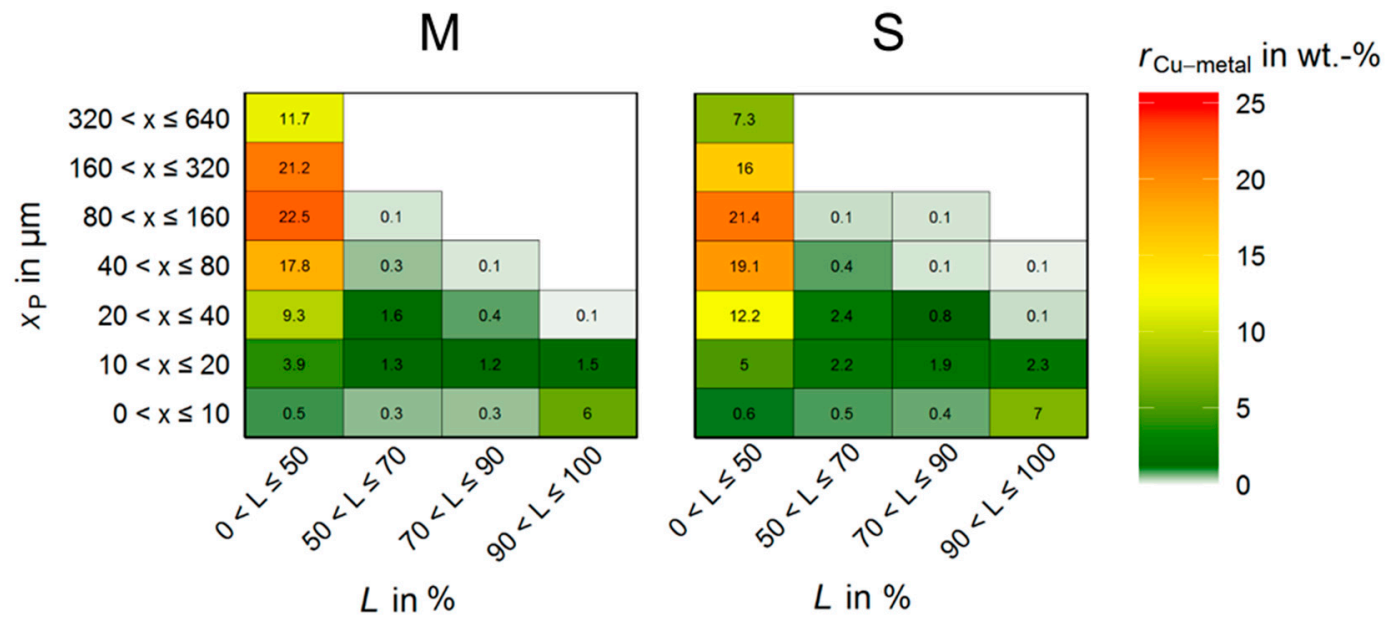

Figure 16. Theoretical recovery $\left(r_{\mathrm{Cu} \text {-metal }}\right)$ of the $\mathrm{Cu}$-metal phase into size $\left(x_{\mathrm{P}}\right)$ and liberation $(L)$ classes for the two main products $M$ and S.

\subsection{Other Elements}

The above evaluations focused on the element $\mathrm{Cu}$, due to its relatively high content. There are other interesting elements present in the investigated material. Table 8 shows the averaged content of some other interesting elements in samples $\mathrm{M}$ and $\mathrm{S}$.

Table 8. Averaged content of various elements in samples M and S measured by MLA.

\begin{tabular}{cccccccc}
\hline Content & $\mathbf{A l}$ & $\mathbf{F e}$ & $\mathbf{C r}$ & $\mathrm{Sn}$ & $\mathbf{P b}$ & $\mathrm{Zn}$ & $\mathbf{N i}$ \\
\hline$\%$ & 17 & 5 & 2 & 2 & 1 & 1 & 0.5 \\
\hline
\end{tabular}

The appearance and deportment of the elements of Table 8 are decisive for the potential recycling of these materials. For samples $\mathrm{M}$ and $\mathrm{S}$, the majority of these elements were distributed between the $\mathrm{Cu}$-rich phases (mainly phases b, c, and d of Table 7) and the Al-rich phases (mainly phase a of Table 7). Some elements were present in other phases with significant amounts. Table 9 gives an overview of the deportment of these elements within samples $\mathrm{M}$ and S.

Table 9. Deportment of various elements between the $\mathrm{Cu}$-rich, Al-rich, and other phases in samples $\mathrm{M}$ and $S$.

\begin{tabular}{cccc}
\hline Element & $\begin{array}{c}\text { Cu-Rich } \\
\mathbf{( \% )}\end{array}$ & $\begin{array}{c}\text { Al-Rich } \\
\mathbf{( \% )}\end{array}$ & $\begin{array}{c}\text { Other Phases } \\
\mathbf{( \% )}\end{array}$ \\
\hline $\mathrm{Al}$ & 29 & 70 & 1 (present as Al metal phase) \\
$\mathrm{Fe}$ & 59 & 21 & 20 (present as iron oxide) \\
$\mathrm{Cr}$ & 43 & 50 & 7 (distributed between various minor phases) \\
$\mathrm{Sn}$ & 30 & - & 70 (present as SnO $_{\text {) }}$ \\
$\mathrm{Pb}$ & 99 & - & 1 (distributed between various minor phases) \\
$\mathrm{Zn}$ & 21 & 62 & 17 (present as $\mathrm{ZnO})$ \\
$\mathrm{Ni}$ & 20 & 78 & 2 (in minor phases) \\
\hline
\end{tabular}

Obviously, the majority of $\mathrm{Al}$ was found in the Al-rich phases; nevertheless, $29 \%$ was found in the $\mathrm{Cu}$-rich phases, and $1 \%$ was present as $\mathrm{Al}$ metal inclusions. For $\mathrm{Fe}$, the main amount was found in the Cu-rich phases, whereas only $21 \%$ was in the Al-rich phases, and $20 \%$ was present as a more or less pure oxide phase. The situation for Sn was totally different, as no Sn was found in the Al-rich phase, while $30 \%$ was present in the $\mathrm{Cu}$-rich phases, and the majority appeared as isolated $\mathrm{SnO}_{2}$ in the sample. $\mathrm{Nearly}$ all $\mathrm{Pb}$ was in the $\mathrm{Cu}$-rich phases. For $\mathrm{Zn}$ and $\mathrm{Ni}$, the majority was found in the Al-rich phases. 
In contrast to $\mathrm{Cu}$, the other elements had no significant appearance in a pure metallic form, while some minor metallic occurrences were found only for $\mathrm{Al}(1 \%)$. This analysis of the deportment of various elements gives a first overview of the different behavior of these elements. A more detailed evaluation of these elements and other trace elements requires the application of additional analysis methods [28].

\section{Discussion}

The slag structure is an important factor for the potential recycling of various valuable metal contents. By adjustment of the process parameters, the structure can be tailor-made for optimizing the recovery of different valuable materials [29].

Firstly, it has to be stated that the results from XCT and MLA are in good agreement. In both cases, clear differences between sample $\mathrm{H}$ on the one hand and sample $\mathrm{M}$ and $\mathrm{S}$ on the other hand were visible. There were two main occurrences of $\mathrm{Cu}$-metal within the slag structure. The first represents the presence of single $\mathrm{Cu}$ droplets within the amorphous matrix in the outer region of the TBRC. These droplets appeared detached from the surrounding amorphous slag structure (see Figure 13). In this region, the cooling rate was rather fast, whereby the droplets could not sink back into the metal phase and were entrapped within the glass-like slag structure. This area is of less importance, as this zone 1 (see Figure 4 ) was determined to sum up to $<1 \mathrm{wt}$. \% of the total mass in the process. Nevertheless, if possible, a further reduction of this zone could be beneficial.

The main slag material showed a structure as identified in samples M and S. Although these two samples originated from different zones of the furnace (zones 2 and 3, see Figure 4), no significant differences between their phase structures were identified. There were two main patterns present in these samples: an Al-rich slag phase and a Cu-rich phase. These main areas showed significant differences regarding their structure and elemental contents. With respect to the solidification order of these main phases, the following assumptions can be made: the Al-rich phase (a) represents the material that solidifies first, followed by the $\mathrm{Cu}$-metal phase. The metal droplets then accumulate as loos agglomerates within the $\mathrm{Cu}$-rich matrix (b and c). Meanwhile the $\mathrm{Cu}$-rich dendritic structures are formed, and phase $b$ and c finally solidify.

The distribution of various valuable metals (e.g., $\mathrm{Au}, \mathrm{Ag}, \mathrm{Ge}, \mathrm{In}$ ) between the different phases of the slag, their deportment, and in which phases they accumulate have to be investigated further [30-32]. Special focus should also be on the effect of the applied slag system [33] and the adjustment of the components to improve the breakage properties with respect to a downstream comminution process [18,34].

By adjusting the cooling rate, the occurrence of the described $\mathrm{Cu}$ droplets has to be minimized. The slag should be kept in a certain temperature window to allow these droplets to settle back onto the metal face at the bottom of the furnace. As these isolated droplets predominantly appear in the outer regions of the furnace and the $\mathrm{Cu}$ content is already lower compared to other regions, the handling and adjustment of this structure is of less importance. By lowering the cooling rate at the same time, the $\mathrm{Cu}$ structure in the inner regions of the slag can also be altered. The target is a better recyclability of the $\mathrm{Cu}$ contents of these materials. A detailed understanding of the occurrence of the main phases and their formation process is necessary for a better understanding of potential parameters to optimize the processability. The structures have to be adjusted to the requirements of the following processes. A potential downstream grinding and separation cascade possibly implies increasing the size of the Cu-metal agglomerates.

In the end, there are two main aspects to improve the recyclability of potential valuable metals within the slag structure. The first point, which is only indirectly linked with the improvement of recyclability, is to reduce these metal contents in the slag by allowing the metal droplets to sink back into the metal phase on the bottom of the furnace. The second point is the adjustment of the slag structure to improve the performance of potential downstream processes [35]. Both require a detailed understanding of the process-parameter-slag-structure relationship and the proposed investigation procedure is able to reveal and quantify the critical effects. Additionally, other observation techniques 
should complement the presented approach to get the full picture [36]. Finally, it has to be stated that the found structures within the slag analyzed via XCT and MLA strongly depend on the applied reactor technology and the resulting flow patterns. These dependencies have to be investigated further.

\section{Conclusions}

The applied analysis methods enabled the characterization of the present material structures of the investigated slag samples. Through the synergetic effect of the two imaging techniques (SEM-based image analysis and X-ray CT), it was possible to identify potential valuable phases and assess the recyclability of these contents. The application of these imaging techniques improves the understanding of the size, shape, and association of the present phases. The $\mathrm{Cu}$-metal contents within the slag samples represent the main valuable component. For a sustainable recycling of these contents, the slag structure has to be optimized and adjusted to the requirements of following processes with the help of various process parameters (e.g., cooling rate). The detailed characterization of the slag structure by imaging processes in combination with fluid flow modeling approaches via computational fluid dynamics represents the basis for an adjusted process optimization and further improvement of recyclability. The main conclusions from the present study in short are as follows:

- The outer amorphous layer of the slag is not suitable for recycling of the metal contents and needs to be minimized.

- The phase structures (e.g., size and shape) showed no differences for sample M (zone 2) and S (zone 3).

- The actual size range of the $\mathrm{Cu}$ metal inclusions is too small for mechanical separation processes. The grain size needs to be increased to improve the recyclability; otherwise, these contents need to be lowered in the slag.

- $\quad$ Other elements, e.g., $\mathrm{Fe}, \mathrm{Sn}, \mathrm{Ni}, \mathrm{Zn}, \mathrm{Pb}$, and $\mathrm{Cr}$, were not found to be present as pure metals in the slag; rather, they were in other oxide or silicate phases.

- An interdisciplinary approach of different fields (i.e., metallurgy, mineral processing, and analytics) is necessary to improve the recyclability of such complex slag materials.

Author Contributions: M.B. conceptualized the paper. N.B. was responsible for the metallurgical tests. T.H. was responsible for sample analysis with a mineral liberation analyzer (MLA) including quality control, data processing, and data evaluation. T.L. was responsible for sample analysis with X-ray computed tomography (XCT) including quality control, data processing, and data evaluation. M.B. and T.L. were responsible for the grinding tests of the material. M.B., N.B., T.L., and T.H. analyzed, interpreted, and collated all results. M.A.R., B.F., and U.A.P. interpreted the results, supervised the work, and supported the preparation of the manuscript. All authors have read and agreed to the published version of the manuscript.

Funding: The authors would like to thank the German Research Foundation (DFG) for funding of the X-ray microscope (Zeiss Xradia 510 Versa) INST 267/129-1.

Conflicts of Interest: The authors declare no conflicts of interest.

\section{References}

1. Worrel, E.; Reuter, M.A. Handbook of Recycling; Elsevier: Waltham, MA, USA, 2014; p. 595.

2. Hageluken, C. Improving metal returns and eco-efficiency in electronics recycling-A holistic approach for interface optimisation between pre-processing and integrated metals smelting and refining. In Proceedings of the 2006 IEEE International Symposium on Electronics and the Environment, Scottsdale, AZ, USA, 8-11 May 2006. [CrossRef]

3. Van Schaik, A.; Reuter, M.A. Chapter 22: Material-Centric (Aluminium and Copper) and Product-Centric (Cars, WEEE, TV, Lamps, Batteries, Catalysts) Recycling and DfR Rules. In Handbook of Recycling; Worrel, E., Reuter, M.A., Eds.; Elsevier: Waltham, MA, USA, 2014; pp. 307-378.

4. Diaz, F.; Flerus, B.; Nagraj, S.; Bokelmann, K.; Stauber, R.; Friedrich, B. Comparative analysis about degradation mechanisms of printed circuit boards (PCBs) in slow and fast pyrolysis: The influence of heating speed. J. Sustain. Metall. 2018, 4, 205-221. [CrossRef] 
5. Borowski, N.; Trentmann, A.; Brinkmann, F.; Stürtz, M.; Friedrich, B. Metallurgical effects of introducing powdered WEEE to a molten slag bath. J. Sustain. Metall. 2018, 4, 233-250. [CrossRef]

6. Bale, C.W.; Bélisle, E.; Chartrand, P.; Decterov, S.A.; Eriksson, G.; Gheribi, A.E.; Hack, K.; Jung, I.H.; Kang, Y.B.; Melançon, J.; et al. FactSage Thermochemical software and databases, 2010-2016. Calphad 2002, 26, 189-228. [CrossRef]

7. Obiso, D.; Kriebitzsch, S.; Reuter, M.; Meyer, B. The importance of viscous and interfacial forces in the hydrodynamics of the top-submerged-lance furnace. Metall. Mater. Trans. B 2019, 50, 2403-2420. [CrossRef]

8. Akashi, M.; Keplinger, O.; Shevchenko, N.; Anders, S.; Reuter, M.A.; Eckert, S. X-ray radioscopic visualization of bubbly flows injected through a top submerged lance into a liquid metal. Metall. Mater. Trans. B 2019, 51, 124-139. [CrossRef]

9. Sutherland, D.N.; Gottlieb, P. Application of automated quantitative mineralogy in mineral processing. Miner. Eng. 1991, 4, 753-762. [CrossRef]

10. Fandrich, R.; Gu, Y.; Burrows, D.; Moeller, K. Modern SEM-based mineral liberation analysis. Int. J. Miner. Process. 2007, 84, 310-320. [CrossRef]

11. Schach, E.; Buchmann, M.; Tolosana-Delgado, R.; Leißner, T.; Kern, M.; van den Boogaart, G.; Rudolph, M.; Peuker, U. Multidimensional characterization of separation processes-part 1: Introducing kernel methods and entropy in the context of mineral processing using SEM-based image analysis. Miner. Eng. 2019, 137, 78-86. [CrossRef]

12. Buchmann, M.; Schach, E.; Tolosana-Delgado, R.; Leißner, T.; Astoveza, J.; Kern, M.; Möckel, R.; Ebert, D.; Rudolph, M.; van den Boogaart, G.; et al. Evaluation of magnetic separation efficiency on a cassiterite-bearing skarn ore by means of integrative SEM-based image and XRF-XRD data analysis. Minerals 2018, 8, 390. [CrossRef]

13. Buchmann, M.; Schach, E.; Leißner, T.; Kern, M.; Mütze, T.; Rudolph, M.; Peuker, U.A.; Tolosana-Delgado, R. Multidimensional characterization of separation processes-part 2: Comparability of separation efficiency. Miner. Eng. 2020, 150, 106284. [CrossRef]

14. Sousa, R.; Simons, B.; Bru, K.; de Sousa, A.B.; Rollinson, G.; Andersen, J.; Martin, M.; Machado Leite, M. Use of mineral liberation quantitative data to assess separation efficiency in mineral processing-Some case studies. Miner. Eng. 2018, 127, 134-142. [CrossRef]

15. Charikinya, E.; Robertson, J.; Platts, A.; Becker, M.; Lamberg, P.; Bradshaw, D. Integration of mineralogical attributes in evaluating sustainability indicators of a magnetic separator. Miner. Eng. 2017, 107, 53-62. [CrossRef]

16. Evans, C.L.; Wightman, E.M.; Manlapig, E.V.; Coulter, B.L. Application of process mineralogy as a tool in sustainable processing. Miner. Eng. 2011, 24, 1242-1248. [CrossRef]

17. Lastra, R. Seven practical application cases of liberation analysis. Int. J. Miner. Process. 2007, 84, $337-347$. [CrossRef]

18. Leißner, T.; Hoang, D.H.; Rudolph, M.; Heinig, T.; Bachmann, K.; Gutzmer, J.; Schubert, H.; Peuker, U.A. A mineral liberation study of grain boundary fracture based on measurements of the surface exposure after milling. Int. J. Miner. Process. 2016, 156, 3-13. [CrossRef]

19. Reyes, F.; Lin, Q.; Cilliers, J.J.; Neethling, S.J. Quantifying mineral liberation by particle grade and surface exposure using X-ray microCT. Miner. Eng. 2018, 125, 75-82. [CrossRef]

20. Little, L.; Mainza, A.N.; Becker, M.; Wiese, J.G. Using mineralogical and particle shape analysis to investigate enhanced mineral liberation through phase boundary fracture. Powder Technol. 2016, 301, 794-804. [CrossRef]

21. Egan, C.K.; Jacques, S.D.; Wilson, M.D.; Veale, M.C.; Seller, P.; Beale, A.M.; Pattrick, R.A.; Withers, P.J.; Cernik, R.J. 3D chemical imaging in the laboratory by hyperspectral X-ray computed tomography. Sci. Rep. 2015, 5, 15979. [CrossRef]

22. Jacques, S.D.; Egan, C.K.; Wilson, M.D.; Veale, M.C.; Seller, P.; Cernik, R.J. A laboratory system for element specific hyperspectral X-ray imaging. Analyst 2013, 138, 755-759. [CrossRef]

23. Furat, O.; Leissner, T.; Ditscherlein, R.; Sedivy, O.; Weber, M.; Bachmann, K.; Gutzmer, J.; Peuker, U.; Schmidt, V. Description of ore particles from X-ray microtomography (XMT) images, supported by scanning electron microscope (SEM)-based image analysis. Microsc. Microanal. 2018, 24, 461-470. [CrossRef]

24. Furat, O.; Leissner, T.; Bachmann, K.; Gutzmer, J.; Peuker, U.; Schmidt, V. Stochastic modeling of multidimensional particle properties using parametric copulas. Microsc. Microanal. 2019, 25, 720-734. [CrossRef] 
25. Reyes, F.; Lin, Q.; Udoudo, O.; Dodds, C.; Lee, P.D.; Neethling, S.J. Calibrated X-ray micro-tomography for mineral ore quantification. Miner. Eng. 2017, 110, 122-130. [CrossRef]

26. Hanna, R.D.; Ketcham, R.A. X-ray computed tomography of planetary materials: A primer and review of recent studies. Geochemistry 2017, 77, 547-572. [CrossRef]

27. Ferrara, G.; Preti, U.; Meloy, T.P. Inclusion shape, mineral texture and liberation. Int. J. Miner. Process. 1989, 27, 295-308. [CrossRef]

28. Cook, N.; Ciobanu, C.; Ehrig, K.; Slattery, A.; Verdugo-Ihl, M.; Courtney-Davies, L.; Gao, W. Advances and opportunities in ore mineralogy. Minerals 2017, 7, 233. [CrossRef]

29. Lennartsson, A.; Engström, F.; Samuelsson, C.; Björkman, B.; Pettersson, J. Large-Scale WEEE recycling integrated in an ore-based Cu-extraction system. J. Sustain. Metall. 2018, 4, 222-232. [CrossRef]

30. Anindya, A.; Swinbourne, D.R.; Reuter, M.A.; Matusewicz, R.W. Distribution of elements between copper and $\mathrm{FeO}-\mathrm{CaO}-\mathrm{SiO}_{2}$ slags during pyrometallurgical processing of WEEE. Miner. Process. Extr. Metall. 2013, 122, 165-173. [CrossRef]

31. Anindya, A.; Swinbourne, D.R.; Reuter, M.A.; Matusewicz, R.W. Distribution of elements between copper and $\mathrm{FeOx}-\mathrm{CaO}-\mathrm{SiO}_{2}$ slags during pyroprocessing of WEEE: Part 2-Indium. Miner. Process. Extr. Metall. 2013, 123, 43-52. [CrossRef]

32. Klemettinen, L.; Avarmaa, K.; O’Brien, H.; Taskinen, P.; Jokilaakso, A. Behavior of tin and antimony in secondary copper smelting process. Minerals 2019, 9, 39. [CrossRef]

33. Avarmaa, K.; Yliaho, S.; Taskinen, P. Recoveries of rare elements Ga, Ge, in and Sn from waste electric and electronic equipment through secondary copper smelting. Waste Manag. 2018, 71, 400-410. [CrossRef]

34. Chris Pistorius, P.; Kotzé, H. Role of silicate phases during comminution of titania slag. Miner. Eng. 2009, 22, 182-189. [CrossRef]

35. Sarrafi, A.; Rahmati, B.; Hassani, H.R.; Shirazi, H.H.A. Recovery of copper from reverberatory furnace slag by flotation. Miner. Eng. 2004, 17, 457-459. [CrossRef]

36. Thyse, E.L.; Akdogan, G.; Olivier, E.J.; O'Connell, J.H.; Neethling, J.H.; Taskinen, P.; Eksteen, J.J. 3D insights into nickel converter matte phases: Direct observations via TEM and FIB SEM tomography. Miner. Eng. 2013, 52, 2-7. [CrossRef] 